\title{
Relato de experiência de monitoria em uma disciplina de análise experimental do comportamento
}

\section{Analysis and experience about the importance of mentoring in the academic enviroment}

\section{Análisis y experiencia sobre la importancia de la mentoría en el entorno académico}

Carla Maria Voitena de Matos' ${ }^{1}$ Alessandra Melânia Gressana Vivan²

[1] [2] FADEP - Faculdade de Pato Branco I Título abreviado: A importância da monitoria no âmbito acadêmico | Endereço para correspondência: Avenida Iguaçu, 826 - Centro. Nova Prata do Iguaçu. CEP: 85685-000 I Email: carla_voitena@hotmail.com I DOI: 10.18761/PAC.2017.003

\begin{abstract}
Resumo: A arte da docência, em sua maioria, é despertada quando o indivíduo está exercendo outro papel, o de aluno. Geralmente, os acadêmicos procuram seus modelos, auxiliando no processo de construção de si, tanto pessoal, quanto profissional. A lei federal de 1968 orienta as diretrizes da educação do ensino superior e regulamenta a função de monitor nas instituições superiores. Esta prática estimula no aluno o desenvolvimento de habilidades que podem ser utilizadas pelo mesmo para um futuro cargo - professor. Percebe-se, então, a importância de destacar a função da monitoria, objetivo desta produção. Para confirmar esta importância, realizou-se uma análise quantitativa com as avaliações das produções acadêmicas - relatórios semanais dos experimentos, e uma análise qualitativa com as autoavaliações solicitadas aos acadêmicos no final do semestre. A monitoria realizou-se no curso de Psicologia da instituição FADEP - Faculdade de Pato Branco, no sudoeste do Paraná, dentro da disciplina de Análise Experimental do Comportamento. Explana-se também, uma breve compilação sobre o Behaviorismo e a Psicologia Experimental, componentes das atividades práticas desenvolvidas. Por fim, expõem-se as discussões e comparações visualizadas na prática e presentes nos resultados. Estes que revelam a importância da atuação de monitores para auxiliar na produção dos relatórios e execução dos experimentos, ato que repercute nas avaliações dos relatórios produzidos, numa perspectiva positiva.
\end{abstract}

Palavras-chave: Análise Experimental do Comportamento, Monitoria, Psicologia. 
Abstract: The art of teaching, for the most part, is awakened when the individual is exercising another role, that of student. Generally, academics seek their models, aiding in the process of self-construction, both personal and professional. The federal law of 1968 guides the guidelines of higher education and regulates the role of monitor in higher institutions. This practice stimulates in the student the development of skills that can be used by him for a future position - teacher. The importance of highlighting the monitoring function, reported in this production, as an objective of this. To confirm this importance, a quantitative analysis was carried out with the academic production evaluations - weekly reports of the experiments, and a qualitative analysis with the self-assessments requested to the academics at the end of the semester. The monitoring took place in the course of Psychology of the institution FADEP - Faculty of Pato Branco, southwest of Paraná, within the discipline of Experimental Analysis of Behavior. It is also explained a brief compilation on Behaviorism and Experimental Psychology, components of the practical activities developed. Finally, we present the discussions and comparisons visualized in practice and present in the results. . These that show the importance of monitoring funcion to assist in the production and execution of the experiments, act that affects in the evaluation of reports, in a positive perspective.

Keywords: Experimental Behavior Analysis, Monitoring, Psychology.

Resumen: El arte de enseñar, en su mayoría, se despierta cuando el individuo está jugando otro papel, el estudiante. En general, los estudiosos buscan sus modelos, la asistencia en el proceso de construcción en sí, tanto personales como profesionales. La ley federal 1968 dirige las directrices de la educación la educación superior y regula la función de supervisión en las instituciones superiores. Esta práctica estimula al estudiante a desarrollar habilidades que pueden ser utilizados por ellos para un futuro post - maestro. Está claro, entonces, la importancia de destacar el papel de la supervisión, meta de esta producción. Para confirmar esta importancia, se llevó a cabo un análisis cuantitativo con las evaluaciones de las producciones académicas - informes semanales de los experimentos, y un análisis cualitativo con autoevaluaciones solicitados a los académicos al final del semestre. El seguimiento se llevó a cabo en el curso de Psicología institución FADEP - Escuela Branco Pato en el sudoeste de Paraná, en el análisis experimental del comportamiento disciplina. También explica una breve recopilación de conductismo y la psicología experimental, componentes desarrollados actividades prácticas. Por último, se establece las discusiones y comparaciones que presentan en la práctica y presentar los resultados. Estos que revelan la importancia de la actuación de monitores para auxiliar en la producción de los informes y ejecución de los experimentos, acto que repercute en las evaluaciones de los informes producidos, en una perspectiva positiva.

Palabras-clave: Análisis experimental del comportamiento, Monitoreo, Psicología. 
O despertar das paixões ocorre através das oportunidades que são aceitas, no decorrer de suas práticas e das atividades propostas. Assim é também com a arte da docência. Com as atividades realizadas no decorrer das formações que os alunos apaixonam-se por um outro papel - o de ser professor.

A monitoria, dentro das instituições, proporciona aos acadêmicos o envolvimento com práticas que são do ambiente docente. Nota-se que nem todos os acadêmicos possuem esta afinidade. Ressalta-se que é de grande valia que se tenha amor pelo o que se faz, pois só assim poder-se-á realizar as atividades diárias sem sobrecarga do cansaço que elas acarretam.

Esta produção textual ocorreu com o objetivo de explanar sobre a prática da monitoria realizada na Faculdade de Pato Branco - FADEP, dentro da disciplina de Análise Experimental do Comportamento, possibilitando ampliar o olhar sobre esta atividade, ressaltando sua importância. Esta que é percebida através do crescimento dos acadêmicos-alunos por terem acesso aos acadêmicos-monitores. Ora pois, são acadêmicos que já passaram por dificuldades similares, e ainda, dedicam parte de seu tempo para auxiliá-los nos obstáculos encontrados. Visto que, a professora, mestre da disciplina, por ter outras atividades maiores, não teria toda a disponibilidade possível para sanar algumas dúvidas dos acadêmicos, que muitas vezes são simplórias.

Fez-se então uma análise quantitativa e uma qualitativa para ressaltar a importância desta prática. Podendo, desta forma, comparar e discutir os resultados encontrados com o que os autores expõem sobre a arte de ensinar, a atividade de monitoria e a modelagem dos comportamentos de produção dos relatórios da disciplina.

\section{Análise experimental do comportamento}

A Psicologia Experimental é uma área que se desenvolveu dentro da psicologia criando a sua importância, ela se dedica à experimentação dos acontecimentos e eventos. Acredita-se que através destas práticas, pode-se chegar a conclusões de grande valia para o conhecimento do homem e de seu jeito de atuar no mundo. Seu objetivo volta-se para a observação dos indivíduos nos experimentos e testes, permitindo resultados satisfatoriamente observáveis (Gauer, 2007).

Seu método, conforme Gauer (2007), "consiste num conjunto de procedimentos de observação; formulação de hipóteses; experimentação (teste de hipóteses); descrição e discussão de resultados, com vistas à identificação de relações causais entre determinadas variáveis" (s.p.).

Desta maneira, a Análise Experimental do Comportamento pode ser vista como uma das práticas da psicologia experimental, já que se utiliza de seu método. A filosofia que embasa a ciência do comportamento é o Behaviorismo, intitulado por B.F. Skinner como Behaviorismo Radical.

Esta teoria - a Análise do Comportamento surgiu como uma proposta para a Psicologia. Seu objeto de estudo, o comportamento, como ele próprio e não como um indicador de alguma outra coisa, ou seja, como indício da existência de um fenômeno que se expressaria através do comportamento. Este compreende-se como a atividade total do organismo, desta forma, engloba-se o funcionamento de todas as partes, dentro da sua complexidade, variedade e realizações. Ele não pode ser entendido de maneira isolada do contexto em que ocorre, não há sentido algum descrever um comportamento sem referenciá-lo ao ambiente em que ocorre, bem como não haveria sentido descrever apenas o ambiente. Para tanto, tornam-se interdependentes os conceitos de comportamento e ambiente, e de resposta e estímulo, ou seja, não há como definir sem referenciar ao outro (Matos, 1995; Todorov, 1982).

A análise experimental do comportamento procura as relações funcionais entre as variáveis, ao controlar as condições experimentais - variáveis de contexto - manipulando as variáveis independentes, que são as mudanças no ambiente. Assim, observam-se os efeitos em variáveis dependentes, ou seja, as mudanças no comportamento (Todorov \& Hanna, 2010).

A prática na disciplina de Análise Experimental do Comportamento, dentro da instituição onde se realizou a pesquisa, busca desenvolver no aluno a observação de comportamento. Objetiva-se fazer com que o acadêmico, nas aulas práticas, perceba 
as variáveis dependentes e independentes presentes no ambiente que agem na mudança do comportamento. Assim, as aulas práticas fortalecem a construção e aplicação teórica visualizadas no decorrer do semestre, pois, ocorrem aulas teóricas paralelamente as práticas. Sob a perspectiva construtivista, "as pré-concepções dos alunos sobre os fenômenos e sua atuação nas aulas práticas são férteis fontes de investigação para os pesquisadores como elucidação do que pensam e como é possível fazê-los progredir no raciocínio e análise dos fenômenos" (Krasilchik, 2000, p.88).

As aulas práticas podem ser definidas de duas formas, de acordo com Masetto (n.d.) "ora demonstrativas quando o professor assume um papel de mostrar como é o fenômeno, ora de aplicação de conceitos aprendidos nas aulas teóricas nos laboratórios ou em estágios" (p.6). Desta forma, revela-se o quão importante é o espaço das aulas práticas, pois instiga um olhar diferenciado, além de que proporciona a percepção da realidade e da aplicação teórica.

Para que o processo de aprendizagem aconteça exige-se, dentre outras coisas, "que permita ao aprendiz entrar em contato com situações concretas e práticas de sua profissão, e da realidade que o envolve" (Masetto, n.d., p.5). A atuação no laboratório de Análise Experimental do Comportamento é uma das formas que permite com que o aprendiz aplique conceitos aprendidos, necessários para sua atuação como profissional da Psicologia.

A aquisição de novos conhecimentos pela interação com o meio pode-se definir como aprendizagem. Esta aquisição resulta-se na modificação do comportamento. A abordagem comportamental compreende no estudo das atividades de um organismo observáveis e privadas, com ênfase na influência das variáveis ambientais na aprendizagem (Cruz, França, Araújo, Barbosa, Silva \& Santos, n.d.).

Como citado por Skinner (1972) "ensinar é o ato de facilitar a aprendizagem" (p.4). Assim, quem ensina é aquele que é capaz de arranjar as contingências de reforço de maneira para facilitar o processo de aprendizagem e não apenas um ser transmissor de conhecimento. Portanto, aquele que "ensina bem" refere-se àquele que facilita a aquisição de uma resposta pelo aprendiz. Desta forma, cada ação, ou melhor, cada comportamento de quem ensina afeta diretamente em quem aprende.
O comportamento operante produz suas consequências e ele é controlado por elas, no sentido de que as consequências é que irão manter ou não o comportamento. "Dizer que as consequências dos comportamentos chega a afetá-los é o mesmo que dizer que as consequências determinarão, em algum grau, se os comportamentos que as produziram ocorrerão ou não outra vez, ou se ocorrerão com maior ou menor frequência" (Moreira \& Medeiros, 2007, p.49).

Com isto, as que aumentam a probabilidade de o comportamento tornar a ocorrer são chamadas de "consequências de reforço". Nesta relação "na qual o organismo emite uma resposta (um comportamento) e produz alterações no ambiente. Quando as alterações no ambiente aumentam a probabilidade de o comportamento que as produziu voltar a ocorrer chamamos tal relação entre o organismo e o ambiente de contingência de reforço" (Moreira \& Medeiros, 2007, p.51). Estas são expressas na forma 'se...então...'.

Desta forma, determina-se se um estímulo é um reforçador, ou se uma consequência é um reforço, considerando sua relação entre o comportamento e consequência. Através da verificação, "se a consequência afeta um determinado comportamento traduzida no aumento de sua probabilidade de ocorrência" (Moreira \& Medeiros, 2007, p.52).

O trabalho de Skinner agregou muito nas práticas, tanto de ensino quanto na terapia. Para ele o aprendizado é envolto por meio dos reforços, extinção e modelagem (Almeida, Lima, Lisboa, Lopes \& Junior, 2013).

Para maior efeito de aprendizagem é importante que os reforçadores sejam emitidos logo após a apresentação do comportamento. Dado que se o reforço ocorrer num grande intervalo de tempo corre-se o risco de o sujeito não discriminar o comportamento emitido. Assim, os reforços devem estar contingentes aos comportamentos emitidos, potencializando a aprendizagem do sujeito. "Numa abordagem comportamental as contingências de reforço são essenciais para que ocorra a aprendizagem e o esquema em que essas contingências surgem é o que vai indicar a frequência do comportamento aprendido" (Souza \& Gomide, 2013, p. 70). Confirmando assim a conexão entre estimulo e resposta, relação significativa para a aprendizagem. 


\section{Monitoria}

A prática da monitoria regulamentou-se a partir da Lei Federal n ${ }^{\circ} 5.540$ de 28/11/1968. Esta que estabelece normas de organização e funcionamento do ensino superior. Em seu artigo 41, relata que, "As universidades deverão criar as funções de monitor para alunos do curso de graduação que se submeterem a provas específicas, nas quais demonstrem capacidade de desempenho em atividades técnico-didáticas de determinada disciplina" (Lei Federal $\left.\mathrm{n}^{\circ} 5.540,1968\right)$. Estimulando assim, que os acadêmicos possam realizar atividades práticas envolventes ao corpo docente, desenvolvendo algumas de suas habilidades importantes para o magistério.

A atividade de ser monitor é complementar à formação, "a monitoria é uma atividade complementar à sala de aula com o intuito de enriquecer a formação acadêmica do aluno de graduação e, instigá-lo, a continuar o processo de formação" (Souza \& Gomide, 2013, p.72).

Desta forma, como colocado em Lei e corroborando com Souza (2011), esta é uma prática que tem por tentativa despertar o interesse do aluno pela carreira docente, promovendo assim, uma cooperação direta entre docente e discente, contribuindo para a melhoria do ensino.

Por conseguinte, esta oportunidade "de aprendizagem nos programas de monitoria torna-se de fundamental importância para a descoberta da vocação docente, evitando, assim, o ingresso nesta carreira, de profissionais que não tenham perfil para esta atividade" (Souza \& Gomide, 2013, p.73).

Cada instituição, portanto, deve estabelecer as atividades a serem realizadas pelos acadêmicos-monitores, e também, em quais disciplinas o projeto de monitoria se aplicaria.

Dentre as atividades realizadas na monitoria, desta instituição e da disciplina de Análise Experimental do Comportamento, citam-se: o acompanhamento das aulas em laboratório e dos experimentos realizados em horários diferenciados das aulas: auxílio, sempre que possível, à responsável por colocar e retirar os sujeitos das caixas de Skinner, auxílio aos acadêmicos em dúvidas durante os experimentos e verificação, juntamente com a professora, se estão sendo realizados adequada- mente; correção dos relatórios: observando a parte teórica - se possui relação com o assunto e com o experimento descrito no mesmo, a metodologia (seguindo as normas ABNT/FADEP) e se haviam os requisitos necessários para a formação do relatório. Posteriormente, ao devolvê-los à professora, a mesma verificava as correções e avaliava-os. E também, auxílio aos acadêmicos na formulação dos gráficos, tabelas e busca de referências bibliográficas para as produções, quando solicitada pelos mesmos.

Ressalta-se que as atividades de correção dos relatórios, realizaram-se residencialmente, as de auxílio aos acadêmicos foram realizadas no espaço da biblioteca, via online (redes sociais) ou em outros locais da faculdade, como as salas de aula ou nas pré-aulas do laboratório. Já as demais, no laboratório de análise experimental.

\section{Materiais e métodos}

Para a análise quantitativa utilizou-se da tabela de notas avaliativas, formulada pela professora da disciplina de Análise Experimental do Comportamento no decorrer do semestre. Em cada semana que os alunos realizavam os experimentos eles deveriam registrá-los, através dos relatórios. Cada relatório possuía sua estrutura, expondo embasamento teórico sobre o experimento realizado, informações sobre o sujeito, o ambiente do laboratório, o aparelho utilizado, o procedimento do experimento, os resultados e as discussões correlacionando a teoria com a prática.

A avaliação dos relatórios consistia em analisar se havia veracidade na teoria e nas informações apresentadas, atendo-se também nos resultados expressos por meio dos gráficos e tabelas, além de avaliar se a formatação do relatório como um todo estava de acordo com as normas institucionais de elaboração de trabalhos. Este era avaliado de 0 a 5 , sendo que, além de todos os quesitos já mencionados anteriormente, avaliava-se a participação e postura no ambiente do laboratório.

Com as notas em mãos, fez-se a média de cada experimento, ou seja, somaram-se as notas de um mesmo relatório de todas as duplas e dividiu-se pela quantidade de duplas em sua respectiva tur- 
ma. Havia duas turmas, sendo que em cada uma existiam 23 duplas.

Criou-se então, gráficos, respectivos às duas turmas em que se acompanhavam as aulas práticas no laboratório. Especificaram-se os relatórios realizados cruzando os dados com as médias de cada um.

Para a avaliação qualitativa, solicitou-se que os acadêmicos enviassem suas autoavaliações, referentes ao trabalho final do semestre, à monitora, com o objetivo de utilizá-las para compilação de dados à produção de artigo.

As autoavaliações consistiam em relatar suas experiências vivenciadas no decorrer do semestre, incluindo também, informações sobre a prática da monitoria e seu funcionamento. Os acadêmicos possuíam a liberdade de expressar suas experiências frente aos experimentos realizados no decorrer do semestre. Os assuntos indicados pela professora que orientavam o trabalho se referiam as experiências com os procedimentos, com o laboratório, monitoras e com a abordagem teórica e prática utilizada.
Para esta análise, leram-se os relatórios de autoavaliação recebido pelos acadêmicos. Numa segunda leitura, grifaram-se as partes em que se relacionavam com a prática da monitoria, a modelagem de seus próprios comportamentos e o crescimento pessoal e profissional dos graduandos. A partir dos destaques realizados, fez-se a análise qualitativa.

\section{Resultados}

Com a coleta dos dados, criaram-se gráficos respectivos as duas turmas que produziram os relatórios após as aulas práticas. Estas que foram realizadas no laboratório da própria instituição.

Estes estão expostos a seguir, especificando-se os relatórios realizados cruzando os dados com as médias de cada um e posteriormente relata-se a análise dos mesmos.

Ressalta-se que os relatórios, expostos nos gráficos, apresentam-se em ordem cronológica de realização.

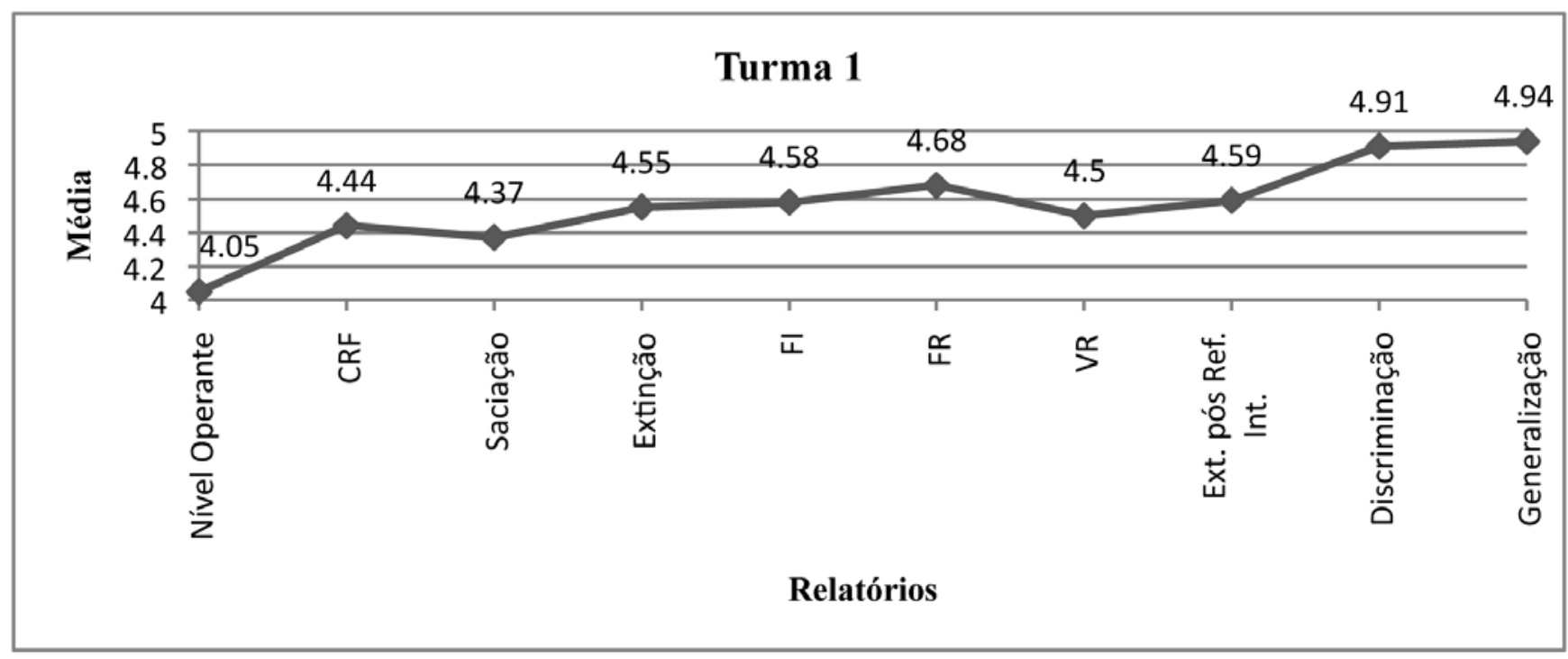

Figura 1. Média de notas dos relatórios produzidos pelos experimentos realizados da Turma 1. 


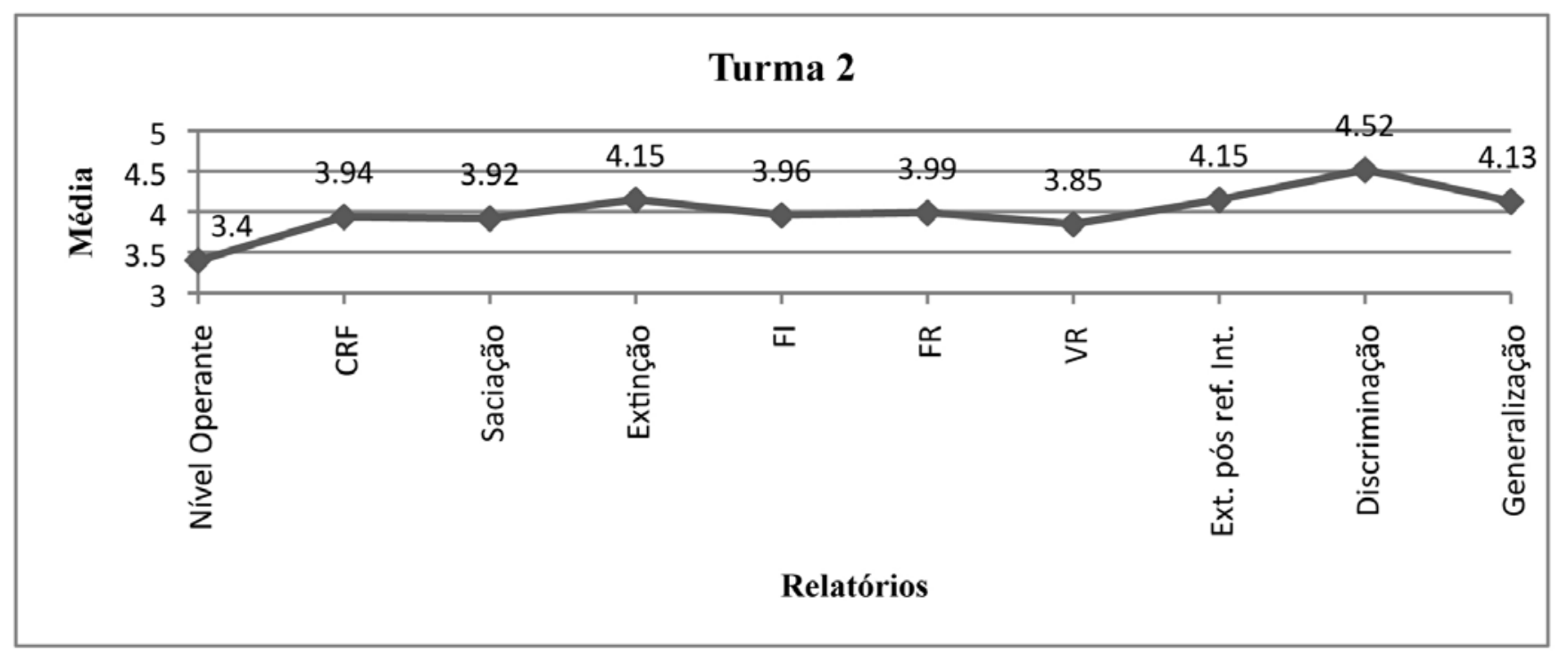

Figura 2. Média de notas dos relatórios produzidos pelos experimentos realizados da Turma 2.

Nota-se que, em ambos os gráficos a linha apresenta-se de maneira crescente. Na Turma 1, as médias variam de 4 a 5, já na Turma 2, ficam entre 3,5 e 4,5. A maior média é evidenciada nas últimas produções, na Turma 1 no relatório de generalização, já na Turma 2 de discriminação. Em contrapartida, a menor média é percebida, em ambos, na primeira produção - nível operante.

Ressalta-se que as maiores notas estão nas últimas produções e as menores no primeiro relatório entregue.

Sob uma análise quantitativa nota-se que a evolução dos acadêmicos foi evidentemente crescente percebe-se que as maiores médias encontram-se nos últimos relatórios entregues.

Os acadêmicos possuíam a liberdade de enviar ou não suas autoavaliações para compor a análise qualitativa. Mesmo solicitando a todos os acadêmicos, apenas seis das duplas enviaram seus relatórios, mas isto não impediu de realizar um estudo sobre as práticas. Acreditando ser pertinente expor o que foi percebido. Nomeou-se como Dupla 1, 2, 3, 4, 5 e 6 as autoavaliações recebidas para serem citadas neste trabalho.

A partir dos destaques realizados nos relatórios, notou-se que em sua maioria a importância de se ter monitores nesta disciplina foi ressaltada.
O trabalho dedicado à monitoria vai além da presença laboratorial. São 10 horas semanais que devem ser dedicadas à esta prática, e várias são as atividades envolvidas. Uma delas é sanar as dúvidas dos acadêmicos e auxiliá-los em suas dificuldades nas produções dos relatórios, como na construção dos gráficos e tabelas e também na busca bibliográfica.

Como exposto pela Dupla 1 "Outro ponto de extrema importância neste processo laboratorial foi a equipe de monitoria que esteve presente a todo momento. Dúvidas recorrentes foram sanadas, experimentos descomplicados e informações valiosas fornecidas.(...) Inclusive, vale ressaltar que encontramos disponibilidade das monitoras em horários variados durante a semana, não apenas em laboratório, para fornecer esclarecimentos sobre as atividades a serem realizadas" (sic).

Eles relatam que conseguiram contato com as monitoras, mesmo em horários distintos, fora do espaço do laboratório. Desta forma, possibilitando sanar as dúvidas durante a formulação dos relatórios. Bem como citado pela Dupla 3 "A elaboração dos gráficos em si foi muito trabalhosa, não tínhamos experiência nas ferramentas do Excel, pedimos ajuda para os colegas da sala para ver se haviam feito da mesma maneira e para uma monitora, até mesmo 
tiramos dúvidas em sala em relação a elas, e agora a elaboração dos mesmos está sendo feito de maneira correta e com mais facilidade" (sic).

Percebe-se que os acadêmicos-alunos tiveram receio inicialmente em pedir auxílio para os acadêmicos-monitores, questionando a professora em relação a confiabilidade para com as colocações das monitoras.

A dupla 4 também cita que buscavam auxílio com as monitoras "buscava informações com monitoras, que auxiliaram muito no início quando não sabíamos como era para serem feitos os relatórios" (sic), eles ressaltam que foi muito pertinente, pois no início quando não se sabiam como fazer os relatórios, as monitoras estavam à disposição para auxiliá-los.

Outro ponto que é importante ressaltar, após a leitura dos relatos, é que assim como se modelava os comportamentos dos sujeitos (ratos), os dos acadêmicos também estavam sendo modificados. Isto não quer dizer que modelavam-se entre si, mas ao contrário, ao estar moldando o comportamento de um sujeito - rato - e com estes experimentos relatar os dados e ações em relatórios semanais, produzindo dados quantitativos e qualitativos de suas práticas, os acadêmicos modelavam os seus próprios comportamentos pelo processo no qual estavam inseridos. Desta forma, modificando seus modos de agir, através de reforçamento. Notam-se as consequências de reforço, tendo em vista que após reforçar tal comportamento ele torna a ocorrer (Moreira \& Medeiros, 2007).

A cada comportamento de produzir um relatório, eles estavam sendo avaliados. Dentro dessas avaliações, eram apontados, tanto pelas monitoras quanto pela professora, os equívocos e falhas nas descrições, comparações e relatos. Ou seja, a cada acerto o reforço - nota - era recebido, a cada falha era orientado uma melhor forma de fazer, eliminando assim os comportamentos indevidos, ou seja, nos erros de produção, tanto normativos quanto textuais.

Conforme colocado pela Dupla 4 "Desse modo as acadêmicas foram modeladas aos exercícios e a produção dos relatórios mediante as consequências desse comportamento e o efeito dos estímulos reforçadores. As consequências nesse caso referem-se ao conhecimento adquirido e as notas são os estímulos reforçadores" (sic).
Confirmando-se com o relato da Dupla 3 "Podemos ainda dizer que a elaboração dos relatórios e a dedicação que tivemos em cada um deles produzimos nossas consequências, que seria a evolução da nota ao decorrer de cada relatório (...)buscamos cada vez mais diminuir nossos erros diante de cada relatório para conseguirmos uma nota ainda melhor em cada relatório feito" (sic).

Com as práticas, produções e buscas constantes de melhoria, nota-se que a adaptação com a rotina, com as avaliações foram necessárias, "Em uma avaliação pessoal pode-se dizer que a medida que tomamos conhecimento sobre o assunto fomos nos adaptando e melhorando nossos relatórios tanto no embasamento teórico quanto na formatação, embora não tenha ficado totalmente dentro das normas impostas pela FADEP. Baseando-se nas notas dos relatórios que fizemos, pode-se dizer que nosso desempenho foi considerado bom" (sic - Dupla 5).

Confirmando os processos de adaptação, a Dupla 2 comenta que tiveram problemas no decorrer das produções com as formatações dos relatórios e gráficos, mas que aos poucos foram se adaptando e tomando forma, "houveram problemas também na formatação dos relatórios e gráficos conforme era pedido pela professora, mas logo foi se adaptando as normas da FADEP e da professora e tomando conhecimento e com isso também houve melhora na elaboração dos relatórios" (sic).

Ressalta-se que "O desafio de produzir um trabalho digno de uma boa nota fez com que nós interagíssemos com objetos (livros e artigos) e outros indivíduos (professores, monitores e pessoas com conhecimento sobre o assunto) com o objetivo de adquirir um repertório de comportamento que fosse capaz de gerar essa consequência" (sic- Dupla 6). Comportamento este, sentido e percebido entre os acadêmicos que estavam em sua busca constante de se aperfeiçoar para melhorar suas produções.

\section{Discussões}

As produções realizadas pelos acadêmicos-alunos eram semanais, portanto, buscava-se que as correções dos relatórios também o fossem. Desta forma, os acadêmicos, poderiam realizar as alterações que 
foram equivocadas em seus relatórios seguintes, evitando manter os mesmos erros em todas as produções.

Com isto, destaca-se a importância da monitoria, como uma forma de auxiliar os trabalhos realizados pela professora. Dado que, os acadêmicos-monitores, tornar-se-iam aptos para apontar os equívocos das normas metodológicas de produção textual, pontuar se os resultados, como gráficos e tabelas, estariam de acordo com o que fora pedido e também se a teoria estava condizente com a prática apresentada no relatório. Desta forma, poder-se-ia haver correções ricas em detalhes e semanais, no máximo quinzenais.

Com tal característica despertar-se-ia ainda mais a vocação de docência nos acadêmicos monitores, dada a importância de atuação dos mesmos. Conforme citado por Souza e Gomide (2013) "evitando, assim, o ingresso nesta carreira de profissionais que não tenham perfil para esta atividade" (p.73). Desta maneira, nota-se que a ação dos acadêmicos monitores, juntamente com as do professor responsável são capazes de facilitar o processo de aprendizagem, pois ambos, ao apontar os equívocos dos acadêmicos em suas produções, arranjam as contingências de reforço afetando diretamente em quem aprende (Skinner, 1972). Esta cooperação direta entre docente e discente contribui para a melhoria do ensino, como colocado em Lei e citado por Souza (2011).

Além disso, os acadêmicos monitores colocam a disposição seu tempo para sanar as dúvidas dos acadêmicos durante a produção dos relatórios, visto que o professor com suas atividades rotineiras não estaria tão acessível quanto aos acadêmicos-monitores que concederam horas semanais para estes atendimentos.

Com esses apontamentos, a cada novo relatório, os acadêmicos foram modelando seu comportamento, mesmo que aos poucos. Pois, a tendência é que a cada apontamento colocado, não seja repetido nos próximos relatórios, aperfeiçoando cada vez mais e ainda, refletindo em suas avaliações. Desta forma, reforçando os comportamentos dos acadêmicos e efetivando a aprendizagem, pois as consequências dos comportamentos são as que confirmam se os mesmos continuarão ou não a ocorrer (Moreira \& Medeiros, 2007).
Isto pode ser evidenciado nos gráficos expostos nos resultados. Pois nos primeiros relatórios os acadêmicos ainda encontravam dificuldades para formulá-los. Com o passar das realizações, eles foram aperfeiçoando, melhorando suas produções. Podendo desta forma, entender que os registros adequados eram mantidos, ao serem reforçados e os inadequados extintos.

Como exposto por Moreira e Medeiros (2007) a contingência reforçadora pode ser expressa na forma "se...então..." Dado que, se os acadêmicos fizerem seus relatórios de acordo com as normas pré-estabelecidas, então, obterão avaliações reforçadoras.

\section{Considerações finais}

Com estas exposições, percebe-se a relação entre o crescimento dos alunos, visualizados em suas produções (relatórios), que a cada semana era aperfeiçoado, aumentando as avaliações com a presença da monitoria. Considerando assim, a prática da monitoria como de grande importância no meio acadêmico. Visto que, com os monitores na disciplina de Análise Experimental do Comportamento, possibilita-se que a correção dos relatórios, seja semanal ou quinzenal, próximas às suas entregas. Por conseguinte a evolução acadêmica é evidente nos resultados.

Atesta-se assim, a hipótese da importância dos acadêmicos monitores na disciplina de Análise Experimental do Comportamento nesta instituição.

Ressalta-se que não são somente os acadêmicos, os quais usufruem da oferta de monitoria, que se engrandecem. Também, os acadêmicos-monitores são possibilitados em desenvolver habilidades que proporcionam o crescimento pessoal e profissional bem como os direcionamentos futuros.

Por mais que seja um caminho desafiante, que necessite de dedicação plena no decorrer das atividades, é uma oportunidade incrível de se aproximar com outras áreas e atividades além do que a graduação pode proporcionar. Ademais, esta prática, proporciona despertar no meio acadêmico o interesse e gosto pela arte da docência. 


\section{Referências}

Almeida, Alana Peixoto; Lima, Flávia Maria Vasconcelos; Lisboa, Sheila Marques; Lopes, Andressa Pereira \& Junior, Alberto José de Amorim Franco (2013). Comparação entre as teorias da aprendizagem de Skinner e Bandura. Cadernos de Graduação - Ciências Biológicas e da Saúde, (Vol.1-3). Retirado de https://periodicos.set.edu.br/index.php/fitsbiosaude/article/ view/905/608

Catania, A. Charles. (1999). Aprendizagem: Comportamento, linguagem e cognição. (4a ed.). Porto Alegre: Artmed

Cruz, Ellen Dias Nicácio da, França, Valtenice de Cássia de Matos, Araújo, Priscilla Anny de, Barbosa, Katiuscia de Azevedo, Silva, Jandilson da, Santos, Natanael Antonio dos. (n.d.). Psicologia da aprendizagem: a utilização da técnica de condicionamento operante dentro e fora do laboratório. X ENCONTRO DE INICIAÇÃO À DOCÊNCIA, PRACUFPB. Retirado de http://www.prac.ufpb.br/ anais/IXEnex/iniciacao/documentos/anais/4. EDUCACAO/4CCHLADPMT02.pdf

Gauer, Gustavo. (2007). Desenvolvimentos da Psicologia Experimental. Universidade Federal do Rio Grande do Sul. Retirado de http://www. fafich.ufmg.br/cogvila/dischistoria/gauer2.pdf

Krasilchik, Myriam. (2000). Reformas e Realidade - o caso do ensino das ciências. São Paulo Perspec. (Vol. 14-1). São Paulo. Retirado de http://www.scielo.br/pdf/spp/v14n1/9805.pdf

Lei Federal n. ${ }^{\circ}$ 5540, de 28 de novembro de 1968. (1968). Fixa normas de organização e funcionamento do ensino superior e sua articulação com a escola média, e dá outras providências. Retirado de http://www2.camara.leg.br/legin/fed/lei/1960-1969/lei-5540-28-novembro-1968-359201-publicacaooriginal-1-pl.html

Masetto, Marcos T. (n.d.). Docência Universitária - Repensando a Aula. Retirado de http://www. adventista.edu.br/_imagens/area_academica/files/docencia-universitaria-repensando-a-aula-i-1.pdf

Matos, Maria Amélia. (1995). O Behaviorismo metodológico e suas relações com o mentalismo e o behaviorismo radical. Instituto TCR Campinas.
Retirado de http://www.itcrcampinas.com.br/ txt/behaviorismometodologico.pdf

Moreira, Márcio Borges, Medeiros, Carlos Augusto de. (2007). Princípios básicos de análise do comportamento. Porto Alegre: Artmed

Skinner, Burrhus. Frederic. (1972). Tecnologia do Ensino. São Paulo. EPU

Souza, Felipe Maciel dos Santos. (2011). Por uma história da Análise do Comportamento no Mato Grosso do Sul. (Dissertação de Mestrado). Pontifícia Universidade Católica de São Paulo. Recuperado de http://www.sapientia.pucsp.br

Souza, Felipe Maciel dos Santos; Gomide, Lucas Bilche. (2013). Experiência de monitoria no ensino de psicologia da aprendizagem. RealizAção - Dourados MS. Vol.1(1). p.67-78. Retirado de http://www.periodicos.ufgd.edu.br/index.php/ realizacao/article/view/2184/1661

Todorov, João Cláudio. (1982). Behaviorismo e análise experimental do comportamento. Cadernos de Análise do Comportamento 3, pp.10-23

Todorov, João Cláudio; Hanna, Elenice S. (2010). Análise do comportamento no Brasil. Psicologia Teoria e Pesquisa. Brasília. Vol. 26. pp. 143153. Retirado de http://www.scielo.br/pdf/ptp/ v26nspe/a13v26ns.pdf

\section{Informações do Artigo}

Histórico do artigo:

Submetido em: 02/09/2017

Aceito em: 08/05/2018

Editor associado: Felipe Leite 